\title{
Shepherding the child: embodied directive sequences in parent-child interactions
}

\author{
Asta Cekaite
}

Linköping University Post Print

N.B.: When citing this work, cite the original article.

Original Publication:

Asta Cekaite, Shepherding the child: embodied directive sequences in parent-child interactions, 2010, TEXT and TALK, (30), 1, 1-25.

http://dx.doi.org/10.1515/TEXT.2010.001

Copyright: Walter de Gruyter

http://www.degruyter.com/

Postprint available at: Linköping University Electronic Press

http://urn.kb.se/resolve?urn=urn:nbn:se:liu:diva-54053 


\section{Shepherding the child: embodied directive sequences in parent-child interactions*}

ASTA CEKAITE

\section{Abstract}

The present study explores how directives are constituted in and through situated verbal, bodily, and spatial practices. The foci are parental directives requesting routine family tasks to be carried out in an immediate situational context and necessitating the child's locomotion from one place to another (e.g., to take a bath, brush his/her teeth). As documented, such directive sequences were designed with what is here called parental shepherding moves, that is, "techniques of the body" (Mauss 1973 [1935]) that monitor the child's body for compliance. Body twist, a form of tactile intervention, was deployed to terminate the child's prior activity and initiate a relevant activity by perceptually reorienting the child in the lived architecture of the home. Tactile and non-tactile steering constituted means for monitoring and controlling the direction, pace, and route of the child's locomotion. Overall, these embodied directives served as multifunctional cultural tools that scaffolded the child into reflexive awareness of the dialogic and embodied characteristics of social action and accountability.

Keywords: directives; parent-child interactions; embodiment; shepherding; tactile engagement; spatial formation.

\section{Introduction}

In the long-standing tradition of research on directives, directives are often conceived of as consisting mainly of spoken language (Ervin-Tripp 1976; Brown and Levinson 1987). Lately, however, research and theorizing on social interaction have accentuated that interaction is embodied and embedded in the social world (Merleau-Ponty 1962; Farnell 1999; 


\section{Asta Cekaite}

C. Goodwin 2000; Linell 2009), arguing that an adequate understanding of communicative practices needs to enlarge the notion of linguistic context to include the embodiment of social actors. Several recent studies on family interactions have demonstrated how the social force and the design of directive sequences rely on participants' careful coordination and deployment of verbal and embodied resources (M. Goodwin 2006; Tulbert and M. Goodwin forthcoming).

In the present study of directive sequences in parent-child interactions, it will be shown how speech, participants' tactile engagement, and spatial formations are all combined in the construction of directive sequences. The foci are directives requesting routine family tasks to be carried out in the immediate situational context and necessitating the child's locomotion from one place to another (to take a bath, brush his/her teeth, etc.). More specifically, distinct formats of embodied actions-here termed body twist, tactile and non-tactile steering - deployed by adults to gain the child's compliance are explored. It will be demonstrated how these resources, together with talk, are "co-expressive of a single inclusive ideational complex" (Kendon 2000: 65) in designing the social force of parental directives. These socioculturally meaningful bodily actions are here termed parental shepherding moves, aimed at controlling and scaffolding the child's body movement as a goal-oriented action that is indispensable to accomplishment of the directive. Body twist and tactile/non-tactile steering can be seen as particular "techniques of the body," that is, the learned and rigorously determined use of the body that society imposes on the individual during the training of a child's bodily activities (Mauss 1973 [1935]: 71). Arguably, the embodied directive sequences provide a locus for the situated, moment-to-moment socialization of the child into accountability through specific bodily and spatial practices, requesting a response of coordinated verbal actions and movements. Overall, the present study contributes to a broader context of research on multimodal interactional practices, which are considered central to co-construction of the parent-child relationship and social order in everyday family life (e.g., de Leon 2000; Neff 2003; M. Goodwin 2006; C. Goodwin 2007; Fasulo et al. 2007; McIlvenny 2009).

\section{Directives in adult-child interactions}

Early studies on family life directives focused on compliance in relation to the speaker's verbal design of a target directive, studied as a single speech act or a dyadic request-uptake/non-uptake pair (Ervin-Tripp 1976; 
Brown and Levinson 1987; Brumark 2006). These studies largely examined directives in family dinner conversations that favor immediate verbal indications of compliance. More recently, analyses have been broadened to encompass the interactional architecture of directives (Ervin-Tripp et al. 1990; Blum-Kulka 1997; Aronsson and Thorell 1999). Ethnographically informed research widened the scope to include directives in a variety of domains of family life (cleaning, hygiene, homework) and emphasized that achieving children's compliance is usually a protracted affair (M. Goodwin 2006; Wingard 2006; Aronsson and Cekaite 2007; Fasulo et al. 2007). M. Goodwin (2006) has demonstrated that directives are better conceptualized as directive trajectories that involve extended sequential development through recipients' response, indicating compliance, rejection, or negotiation of the request. In addition to verbal resources, she highlighted the interactional significance of affective stances and changing participation frameworks over time, including participants' facing formations (Kendon 1990), permitting direct face-to-face communication, and the successive establishment of a mutual activity orientation, as some of the key factors for the establishment of social accountability and the organization of successful directive trajectories.

When designing directives, parents need to handle the divergent issues of regulation and control, simultaneously preserving the atmosphere of social ambience (Blum-Kulka 1997). Thus, the shape of parental directives provides information on the parental perspectives on children's autonomy and agency (M. Goodwin 2006; Fasulo et al. 2007). Parental intervention and assistance may be upgraded or mitigated through systematic verbal practices that frame the activity as a collaborative venture on the part of the caregiver and the child (e.g., "solidarity politeness," Scollon and Scollon 1981). Prosody, affective stances, and embodied action have also been observed to be critical to the interactional bearing of parental intervention (M. Goodwin 2006; Aronsson and Cekaite 2007; Fasulo et al. 2007; McIlvenny 2009).

Directives, as shown, provide linguistic and cultural tools by which parents socialize children into preferred ways of thinking and acting (M. Goodwin 2006; Wingard 2006). Furthermore, directive trajectories can be seen as a social site for socialization into mutual accountability and trust, where relations between family members as independent or interdependent, responsible, trustable or irresponsible are enacted, assessed, and reshaped. Trust is a major principle in the organization of social relations and social interactions (Markova et al. 2008). In contemporary sociocultural theorizing on trust, diverse forms of trust are conceptualized along the dimensions of direct (instantaneous, taken-for-granted) and 
reflective trust (based on an intersubjective "understanding of the perspective of Other") (Gillespie 2008: 276; Markova et al. 2008). An intimate and instantaneous sense of self/other reciprocity and mutual affective attunement-basic sense of trust - characterizes the (early) caregiverchild relation (Markova et al. 2008; Erikson 1968), which is highly asymmetric and based on the child's physical and social dependency on the caregiver/parent, who is thus able to use powerful (bodily and verbal) actions of care and control. Across the developmental span, it is theorized that the child, through widening social relations, develops reflective forms of trust - a sense of mutual moral obligation and responsibility. Thus far, however, the situated, processual, and embodied character of the child's socialization and development of micro-reflective trust through everyday family interactions has received relatively little attention. By focusing on directive sequences as methods through which the parent pursues the child's autonomy in different domains of personal and domestic tasks, the present study aims to discuss some of the ways in which directives serve as embodied tools in the moment-to-moment socialization into the intersubjective understanding of responsibility and obligation-i.e., reflective forms of trust.

\section{Embodiment in social interaction}

Viewed in relation to dialogical theories on human interaction and sense making, the embodied process of social interaction hinges on the coordinated production and perception of actions (movements and talk) in time and space, i.e., within socioculturally meaningful corporeal units of participation (Merleau-Ponty 1962; Hanks 1996; C. Goodwin 2000). This mutual relationship between body and the world means that the lived body has a twofold character, being able to see and touch, on the one hand, and being seen or touched, on the other (Merleau-Ponty 1962; Lindblom 2007). In line with Merleau-Ponty's notion of “body-inmotion," research on embodied interactions has contributed substantially to the understanding of body as a visually available, temporally unfolding field for coordinating social interaction (C. Goodwin 2000). Eye contact is seen as a primary method by which participants can monitor and coordinate their behavior, allowing them to treat each other's bodies as mutually accessible visual fields for the ongoing co-production of intentional action.

Thus far, the interactional role of touch in coordinating embodied interaction is the least researched area, despite the fact that touch, among 
other communicative modalities, is of special importance, as it is intrinsically relational and dialogic. The relationality of tactile engagement involves communicative potentials and the incipient indexing of affective and social relations through touch (Hertenstein 2002). Simply stated, one cannot touch the other without being touched (Hertenstein 2002; Lindblom 2007). Letting another touch oneself escalates the balance of intimacy (Jones and Yarborough 1985). Thus far, the communicative role of touch has largely been examined in monological terms, as predetermined by the (causal) relation between the form tactile engagement takes and the social relation/status of the co-participants. Control touches in adult interactions (i.e., attempts to influence and direct the behavior of another) have been categorized across a wide continuum of affectively shaped actions of specific bodily design, from "positive" forms of touch, designed to ingratiate oneself (caressing, hugging), to "negative" touches of interpersonal dominance and intimidation (spatial and chronemic violations, such as fiercely shoving, holding the recipient) (Guerrero and Floyd 2006). In research on adult-child interactions, the psychological developmental benefits rather than symbolic functions of touch have been foregrounded (but see Goodwin 2006; McIlvenny 2009).

The relative neglect of embodiment in adult-child interactions can be seen as closely related to the logocentricity that pervades the canonical (Western middle-class) model of caregiver-child interactions. These learning and socialization contexts are characterized as primarily oriented toward an exchange of verbal messages within face-to-face positionings of the participants. Multimodality is acknowledged, but mainly as a compensatory mode that developmentally transitions toward the child's verbal performance (for related criticism, see Uzgiris 2000). Lately, this overgeneralization has been challenged by detailed micro-ethnographic interactional studies in non-Western developmental contexts, arguing that the emphasis on talk in caregiver-child interaction overlooks the communicative and socializing significance of embodied resources, including information provided by gaze, postural changes, and touch (e.g., Rogoff 1990; de Leon 2000; Neff 2003).

Not neglecting the importance of talk in caregiver-child interactions, the present study will highlight situated embodied practices, as part and parcel of daily Swedish middle-class family interactions. In the analyses below, I will explore the design of directive sequences assembled in and through habitual verbal, bodily, and spatial practices. Such insights, it is argued, may provide a deeper understanding of socialization as inextricably reliant on the techniques of the body through which communicative practices are realized. 


\section{Method}

\subsection{Data}

The present study is based on a video ethnography of family life in Sweden that has documented the ways in which family members engage in the manifold tasks, activities, and responsibilities of households in which middle-class dual-earner parents are expected to juggle diverse and at times conflicting demands. ${ }^{1}$ Eight families, including 23 children of 3-16 years of age, have been documented. Each family features at least one child who is between 8 and 10 years old, and who has one or two siblings. An array of ethnographic methods was used to document everyday routines and events (Ochs et al. 2006). Each family was filmed for about a week using two cameras, and a third team member made notes, tracking family members' activities and locomotion within the house.

\subsection{Unit of analysis}

On the basis of activity logs and repeated viewings of the video, directive trajectories (90), requesting routine actions to be carried out in the immediate situational context (i.e., parents asking children to perform domestic tasks: to take a bath, brush their teeth, dress themselves, etc.) were identified. These directives usually made it necessary for a child to move from one place to another. Locomotion was thus a necessary element of the directive sequence, indispensable to the accomplishment of the requested action. In all eight families, these directives were recurrently designed as a complex of embodied actions, monitoring the child's body for compliance. Thirty-two directive trajectories were assembled through bodily practices that I term a body twist (i.e., tactile reorientation of the child's body positioning and attentional focus), and tactile and non-tactile steering of the child's bodily movement across the lived architecture of the home in the direction of the appointed goal. These conventionalized embodied practices targeted both girls and boys, aged between 3 and $12 .^{2}$

In the present article, a selection of four directive sequences, covering key variations of the phenomenon, is discussed. In line with a multimodal dialogical approach to human interaction and sense making (C. Goodwin 2000), the directive trajectories are studied as socioculturally meaningful, situated activity systems (i.e., "communicative projects" of getting things done, Linell 2009) consequential for the constitution of social roles and categories within families in their everyday interactions. 


\section{Analysis}

\subsection{Shepherding: body twist and tactile steering of the child's locomotion}

In the following, I will explore the key features that characterize shepherding, including body twist and tactile steering. Importantly, these forms of tactile engagement are interactional and dialogic (Linell 2009) in that they, by being designed to influence the recipient's behavior, solicit specific forms of reciprocity and uptake. Shepherding, starting with the initial body twist, was a recurrent strategy deployed to bring about the child's compliance with the parent's request when verbal directives had failed. Body twist involved the parent's tactile intervention aimed at physically terminating the child's (alternative) activity through reorientation of the child's body positioning and attentional focus toward a targetaction-relevant location. The embodied directives were recurrently embedded within what here is called a C-formation - an embodied formation of control (cf. Kendon 1990 on F-formation system; M. Goodwin 2006; Mcllvenny 2009). Assembled as a specific spatial-orientational patternparent positioned behind the child - the C-formation provided the parent with affordances to (visually and physically) control and scaffold the child's actions.

Excerpt (1) involves a morning routine, when a mother and two children engage in various hygiene tasks. The mother is making the bed and talking with the children. Standing at some distance from her daughter, the mother issues a verbal directive (designed as an interrogative), requesting that Ida go to the bathroom and use the toilet.

(1) Mother (M), Ida (I; a girl, 5 y.), Ludvig (L; a boy, 3 y.) ${ }^{3}$

$1 \mathrm{M}$ : ska du gå in och $\uparrow$ kissa Ida should you go and $\uparrow$ wee-wee Ida ((making bed))

2 L: $n e j$

no

3 M: Ida. heter du $\uparrow I d a n u$

Ida. is your name $\uparrow$ Ida now ((to Ludvig))

$4 \quad$ L: $\quad[a \uparrow a$

5 M: $\quad[($ goes to Ida $))$

6 M: aja. yeah.

7 L: heh heh heh

8 I: [Ludvig ska gå in och kissa:

[Ludvig should go and wee-wee:

9 M: [((embraces Ida) $)$ 
$10 \mathrm{M}: \operatorname{kom}() \quad.[\mathrm{xx}$

$11 \mathrm{~L}: \quad[n e: e j$ [no:oh ((to Ida))

12 M: gå in och kissa nu Ida go and wee-wee now Ida ((shoves Ida, takes her clothes))

13 L: heh heh heh

$14 \mathrm{M}$ : ((steers Ida to the bathroom from behind))

$15 \mathrm{M}: \quad s \underline{a}(1.5)$ så so (1.5) so ((steering Ida to the bathroom))

$16 \mathrm{M}: \quad>$ stänger dörren här. kissa nu!< $>$ shutting the door here. wee-wee now!< ((shoves Ida into the bathroom and closes door))

The mother's verbal turn in line 1 is an implicit directive, requesting that Ida go into the bathroom and use the toilet. However, Ida, fully visible to her mother, does not respond to her mother; instead she preserves her interactional engagement with Ludvig. While the mother and the children mildly tease each other (lines 2-8), the mother finishes making the bed and moves toward Ida (lines 5-9). Approaching Ida, the mother reaches out her arms toward her daughter, projecting the onset of an embrace (see Picture 1, Figure 1).

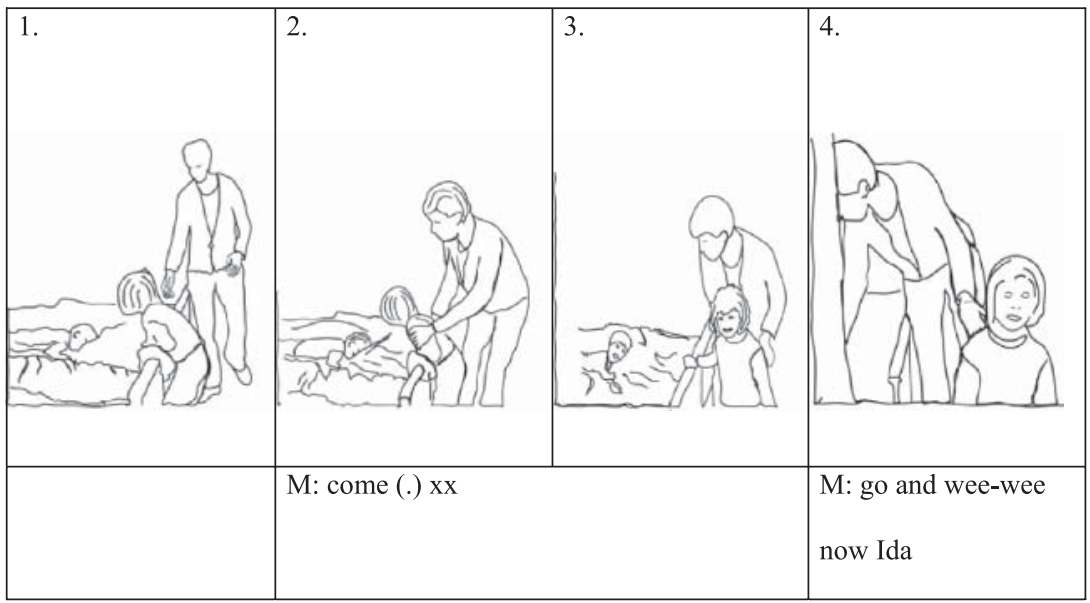

Figure 1. Body twist

Simultaneously with Ida's teasing response to Ludvig (line 8), the mother embraces Ida from behind and initiates a body twist (Picture 2, Figure 1). Holding her hands on her daughter's shoulders, she turns the 
daughter's upper body segment toward the door (target-activity-relevant location). The body twist is coupled with the mother's verbal directive kom 'come on' (line 10), which topicalizes the request for locomotion. As a result of the mother's embodied intervention, Ida changes her entire bodily orientation and attentional focus (Pictures 2-4, Figure 1). Let us look more closely at the interactional characteristics of this embodied action.

Body twist (initiated by the parent) has some features in common with the self-initiated postural configuration called body torque (on body torque, see Schegloff 1998). They both index divergent interactional involvements through postural instability (configured as "twisting of the upper trunk relative to the planted position of the legs," Schegloff 1998: 544). Such postural instability needs to be resolved by bringing the head and the lower body segment into convergent alignment. In contrast to body torque, where the more strongly projected resolution involves resuming the prior activity (indicated by the position of the lower body segment), when submitted to a body twist, the child usually realigns her lower body with regard to the upper body segment, as solicited by the adult. As shown in Pictures 2-4, smooth resolution of the body twist is a dialogic enterprise: While the mother's touch engages only the daughter's upper body, it is employed to elicit recipiency and targets the whole body for action. By submitting to and carrying through the body twist, Ida signals a shift in her interactional engagement: she terminates her current activity (verbal argument with her little brother) and aligns in a participation framework where action, requested by the parent (locomotion to the bathroom), is in focus.

The body twist dynamically reshapes the corporeal field of participants' action and the child's perceptual positioning. It is initiated from and arranges the parent and the child into a $\mathrm{C}$-formation (embodied formation of control), which is assembled as a linear spatial arrangement, the parent positioned behind the child (Pictures 2 and 3). As shown in previous studies of directives (M. Goodwin 2006), facing formation (F-formation) -in which co-participants are visibly co-present to each other and are provided with "equal, direct and exclusive access" to each other's transactional segment (Kendon 1990: 209) — serves as an important means for invoking the accountability of the child and subsequent achievement of compliance. In contrast, C-formation is structured by an asymmetry in the access that co-participants have to each other's transactional segments, and the visual displays of each other's body. In entering into a C-formation, participants form a behavioral system within which the parent occupies a spatial position that provides her with exclusive (visual and bodily) access to the child's body, the child positioned to submit her 
bodily actions to the scrutiny and control of the parent. ${ }^{4}$ Given the apparent asymmetry, the C-formation allows for unilateral control over the co-participant's (child's) actions.

As demonstrated in Excerpt (1), the body twist is then smoothly transformed into a light shove (Picture 4, Figure 1). This touch behavior initiates a new segment of the embodied directive sequence, that of tactile steering of the child's locomotion. The shove (i) prompts the preferred action (i.e., locomotion) and (ii) projects the desired goal of movement (i.e., toward the bathroom). The mother's verbal directive, an imperative demanding the daughter's individual action within a narrowed time frame $n u$ 'now' (line 10), is thereby embedded within an embodied move toward carrying out such ends.

This recasting of the participants' bodies makes specific actions possible, while others are not. Simply, with her body, the mother prevents the girls from moving in an unexpected direction: She follows the child toward the door, holding her hands on the girl's shoulders (steering her from behind) all the way to the bathroom door. Still holding one hand on the daughter's shoulders, she opens the bathroom door, with a light shove steers the daughter inside the bathroom and closes the door (Picture 1, Figure 2). In addition to the mother's body, the material objects in the lived architecture of the home are employed both as orientational markers and as material constraints delineating the trajectory of locomotion.

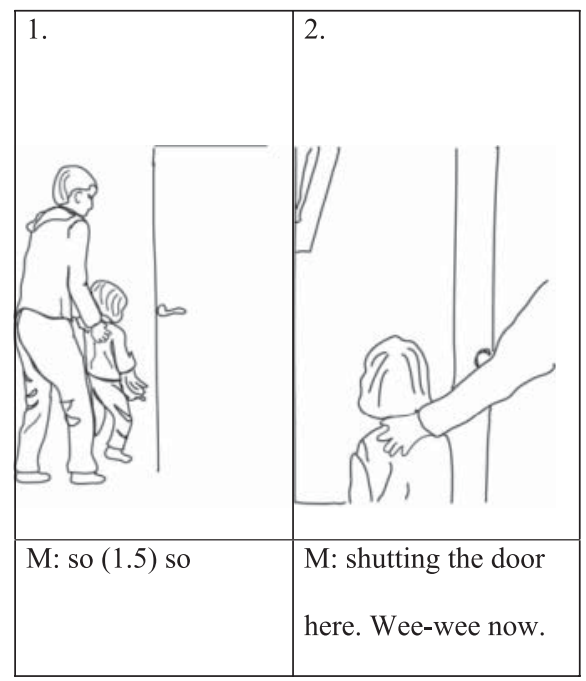

Figure 2. Tactile steering 
A distinguishing feature of tactile steering was that the phenomenon in focus was instantiated through sustained forms of touches that were communicatively related to one another within the same directive sequence. It consisted of several touches, aimed to prompt, initiate, and control the direction, route, and pace of the child's movement. Throughout the concerted trajectory of movement, the participants were perceptually (i.e., corporeally) co-present: the parent and the child moved in a C-formation, maintaining its integrity (partly) through the mother's tactile engagement (hand on daughter's shoulder, Picture 1, Figure 2) (cf. Kendon 1990: 222). By cooperatively maneuvering their bodies, the participants displayed that they are governed by the same set of general considerations, aligned within the same activity frame: The parent displayed her control and scaffolding, and the child, by moving in concert with her mother, displayed her compliance with the parental embodied request.

As demonstrated in Excerpt (1), the directive sequence develops from the mother's initial verbal directive (line 1), which can be seen as indexical of the parent's perspective on the child as trustable as regards bringing about the requested action on her own. Importantly, in response to the daughter's noncompliance, the directive is transformed into parental intervention through tactile forms of shepherding, indicating that the parent distrusts the child's willingness to autonomously initiate the requested action. Notably, tactile shepherding provides a powerful and efficient, but simultaneously inconspicuous, strategy of control that, although constituted through tactile engagement and asymmetric C-formation, does not "noticeably" violate the personal integrity of the child: Acting upon the basic reciprocal trust established in this intimate (but asymmetric) relation, and the young child's recurrent bodily dependence on the parent (cf. Markova et al. 2008), the parent is able to exert her care and control. ${ }^{5}$

\subsection{Differences in quality and design of touch}

Tactile intervention was exerted in different ways and degrees, and was instantiated through different qualities of touch (light, gentle touch or conversely, firm embrace) and the duration of tactile engagement (e.g., sustained throughout the route of locomotion). In the following, I will explicate how the tactile design of directive sequences affords varying types of co-participation, control, and scaffolding with respect to the requested activity. The next episode (Excerpt [2]) occurs during a morning routine, when the mother dresses her three-year-old son in his room. 
(2) Mother (M), Ida (I; a girl, 5 y.), Ludvig (L; a boy, 3 y.)

$1 \quad$ L: jag är ki:ssnödig I have to wee-wee: ((sad voice))

2 M: ah. (.) här (.) kom här i (x) (0.5) yah. (.) here (.) put on (x) (0.5) ((dressing Ludvig))

3 M: IDA! (2)

$4 \quad$ M: vi går in och kissar före Ida då we'll go and wee-wee before Ida then ((dressing Ludvig))

$5 \quad \mathrm{~L}: \quad m h$ ((is reaching toward toys))

$6 \quad$ M: $\quad m h .[\langle k \underline{k}$ m då! $\rangle$

$7 \quad$ mh. [<come now! $\rangle$ [((embraces Ludvig, turns him around $))$

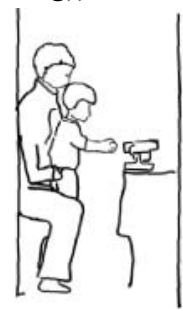

8 L: ((starts running))

9 M: ((follows Ludvig steering him from behind

10 toward the bathroom))

$11 \mathrm{M}:{ }^{\circ}$ det tar sain ti: $h h d^{\circ}$

12 "it takes so much ti:hhme (("exhausted" voice))

13 M: ((steers Ludvig toward bathroom))

$14 \quad \mathrm{~L}: \quad N \ddot{A} N \ddot{A} N \ddot{A}$ ((to Ida))

15 M: shhhh

16 M: ((Mother and Ludvig go inside the bathroom, she closes

17 the door))

The mother acknowledges Ludvig's announcement of trouble (he has to wee-wee, line 1) and tells him that they will go and use the toilet before Ida (line 4). Her utterance is a verbal directive announcing a new, collaborative action (inclusive pronoun we). While Ludvig gives his verbal assent (line 5), there is a marked misalignment in his verbal and nonverbal conduct. Instead of initiating the requested activity (going to wee-wee), Ludvig takes a step forward and reaches out for some toys that are lying on the table in the opposite direction from the door. 
Upon this, the mother issues a directive (comprising imperative and particle kom då 'come now'), verbally indicating the absence of the relevant action on the boy's part. The mother also makes use of an embodied strategy to align the child with the task (lines 6 and 7).

She embraces Ludvig by firmly getting hold of his body trunk from behind, pulls him away from the toys, and reorients his body toward the door. Multiple interactional functions can be seen to co-inhabit the mother's actions, those of control as well as of socialization toward action and accountability. The mother not only terminates the boy's alternative activity and solicits a new course of action, but also bodily "corrects" the misalignment in the three-year-old boy's activities, which is manifested in his verbal consent to compliance and nonverbally taken alternative action.

Subsequently, the mother engages in tactile steering of the child's movements all the way to the bathroom door. Holding the child from behind, i.e., using touch to maintain a mobile C-formation, she firmly controls the direction and pace of the child's movement (lines 9-17). The three-year-old's movements toward the bathroom indicate his recognition and interpretation of these techniques of the body as implicit ways of scaffolding his bodily actions with regard to his mother's request.

As can be seen, the mother's tactile engagement allows a markedly higher degree of tactile co-participation and control of the child's body in that she deploys a firm embrace (as compared with Excerpt [1]), physically constraining the child's possibilities to move in an unexpected direction. Tactile steering (designed as a mobile $\mathrm{C}$-formation) is transformed into covered effective assistance that gives the child limited influence on the process of locomotion. Noticeably, the directive sequence, apart from the mother's "tired" comment and resigned tone of voice (lines 11 and 12), preserves a rather neutral affective indexing, the mother's intervention verbally rather downplayed, retaining the character of a mundane event, nondisruptive of the ordinary flow of "getting things done" in family life. ${ }^{6}$ In addition to achieving compliance with the parental request, embodied directives, through the bodily co-presence of the parent, simultaneously scaffold the child's corporeal awareness of the targetactivity-relevant actions (allowing projection of the embodied self as part of a collaborative activity trajectory), emphasizing bodily actions and talk as a single expressive medium through which participation in communicative practices is interpreted and realized.

\subsection{Non-tactile steering: projected locomotion}

Other formats of shepherding have a non-tactile, but nevertheless embodied design. In the present study, non-tactile steering of the child's 
locomotion was exercised by means of the parent's advancement toward the child, while following him/her from behind. Embedded within the (verbal) activity framework, the spatial practices of the parent's walking and following the child, while both participants actively work to sustain a mobile C-formation, suffice as means for projecting and steering the direction, route, and pace of the child's locomotion.

The following directive sequence involves a mother and a preadolescent child (nine-year-old son). Before this episode, the parents and Jens were discussing their plans for the day.

(3) Mother (M), Father (F), Jens (J; a boy, 9 y.). Saturday morning.

$1 \quad \mathrm{M}$ : då tar vi och (.) xx oss tycker $j \underline{a}$ then we'll (.) xx ourselves $\underline{I}$ think ((looking at Jens))

2 J: ((starts moving from the kitchen))

$3 \quad \mathrm{~F}:$ stoppa in $[\mathrm{x}$ put in $\quad[\mathrm{x}(($ to Jens $))$

4 M: $\quad$ [borsta tänderna också (.) först och främst [brush your teeth too (.) that's the first thing to do

5 J: ((nods while moving from the kitchen, but then turns

6 around and goes back to his mother in the kitchen))

7 J: >varför det?< $>$ why's that? $<(($ smiling, looks at mother $))$

8 M: ((starts walking towards Jens))

9 M: du har ätit socker dessutom xx då får man borsta tänderna you've eaten sugar furthermore $\mathrm{xx}$ then you have to brush your teeth

10 M: ((embraces Jens, starts turning him around))

$11 \mathrm{~J}: \quad b[l e$

$12 \mathrm{M}$ : [visst $\mathrm{y}[\mathrm{uk}(($ smiling))

[sure ((completes body twist))

13 M: ((follows Jens from behind and watches him open the 14 bathroom door))

In line 1, the mother, while gazing at Jens, sums up the family plans for the day and issues a directive, addressed to include all family members. This brings about Jens's compliance (he starts moving toward the door). Father and mother announce further directives (lines 3 and 4), which in their unmitigated form indicate their routine, non-negotiable character. Although initially Jens's head nod indexes his minimal assent (line 5), he returns to the kitchen and, facing his mother, teasingly challenges her, soliciting a reason for brushing one's teeth (lines 5-7).

Noticeably, the mother's response to Jens's challenge comprises both a verbal justification (lines 8 and 9) and nonverbal actions that designate 


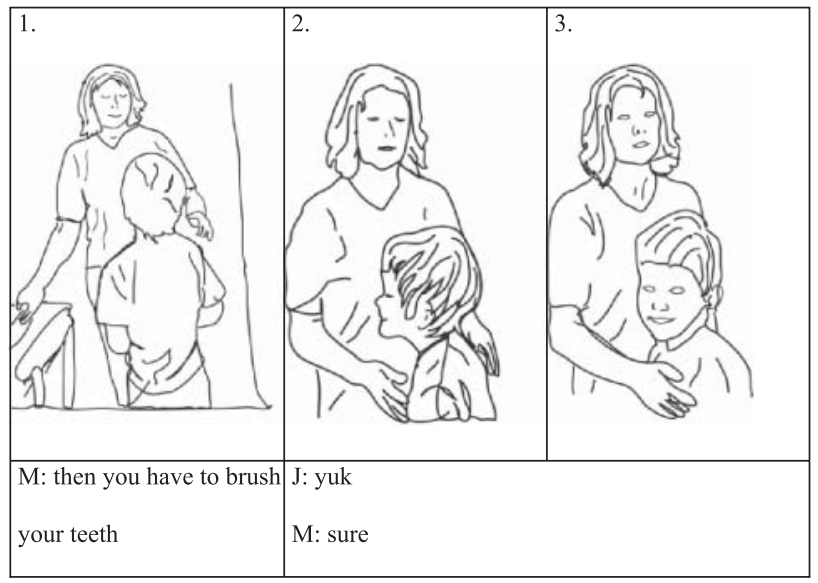

Figure 3. Body twist

her readiness to intervene in the boy's noncompliance. She starts moving toward the boy and establishes the facing-formation (M. Goodwin 2006). Moreover, the mother's gesture, performed within the visual perceptual field of her son, projects and is recognizable as the onset of a body twist, which is accomplished when she places her hands on Jens's shoulders and turns him around (Pictures 1-3, Figure 3).

By forcing her son to change his bodily orientation, she terminates his ongoing course of action (that of challenging his mother) and enforces the shift of his attentional focus toward the location of the target activity (the door leading from the kitchen to the bathroom). Through the body twist, she aligns him in a C-formation (positioning her behind her son) that provides her with privileged visual access to the child's actions. The boy accepts the embodied directive by playfully carrying through the enforced body twist, and initiates locomotion toward the bathroom. Interestingly, on the way to the bathroom, the mother withdraws her tactile engagement, but still monitors the boy's movements by following closely after him and observing while he opens the bathroom door (Pictures 1 and 2, Figure 4).

In contrast to previous examples (Excerpts [1] and [2]), the parent engages in different, non-tactile steering of the child's locomotion toward the location of the target activity, exerting less bodily control and assigning the boy a higher degree of autonomy and freedom. Non-tactile steering (assembled as a C-formation) co-inhabits multiple functions that allow projection of the child's locomotion (Picture 1, Figure 4). The 


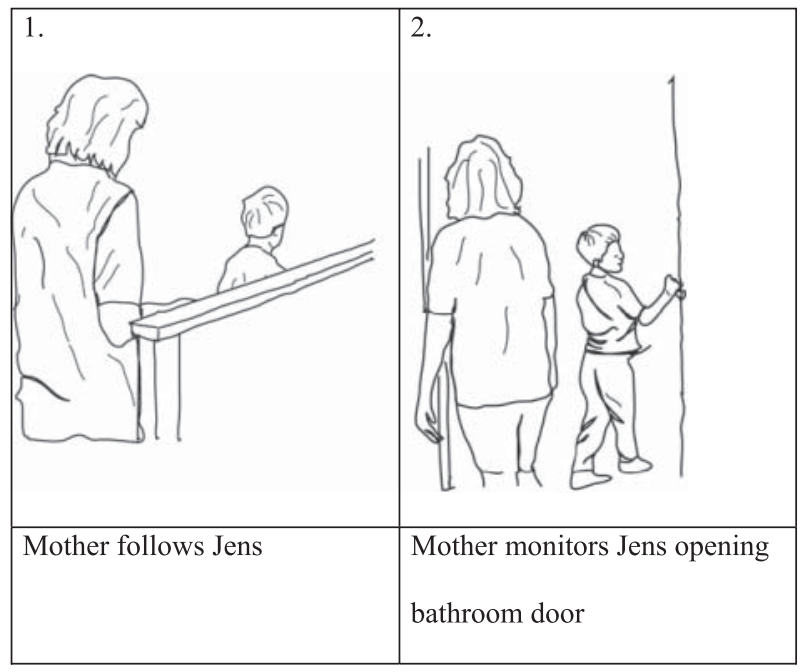

Figure 4. Non-tactile steering

parent's body in motion (behind the child) (i) accentuates the requested action (locomotion), (ii) constrains and affords availabilities for the child's action, continuously projecting its route and direction, in a way that particular embodied actions become possible and others impossible. The mother's advancement toward the location of the target activity constitutes an effective means of steering and controlling the child's actions: By cooperatively maintaining a C-formation and a certain physical distance between each other throughout their movement trajectory, they are able to advance toward the location of the target activity.

Steering (directing) children throughout the socially and materially sedimented surroundings can thus be done using relatively open or less negotiable strategies. By allowing the route of locomotion to go in an outlined, or conversely in a less predictable, direction, the tactile versus non-tactile design of steering assigns recipients different degrees of autonomy and responsibility (and can be seen as situated embodied displays of parental trust/distrust). Similarly to the verbal means, embodied features of conduct provide means for displaying different degrees of imposition and coerciveness.

\subsection{Withdrawn body twist and non-tactile steering}

Excerpt (4) presents yet another case of (non-tactile) shepherding and projected locomotion. I will especially highlight the participants' orienta- 
tion to the conventionalized and mutually recognizable significance of these embodied practices. The present episode involves an extended directive sequence during a bedtime routine. Prior to the episode, the mother has issued numerous directives ( $k$ om 'come') asking her fouryear-old daughter to go to her room.

(4) Mother (M), sisters Sara (S; 4 y.) and Kristin (K; 8 y.), Father (F). Sara sits on the floor playing with a toy boat. Mother is in the laundry room nearby.

1 M: ko:m nu Sara co:me on now Sara ((weary, "tired" voice))

2 ((mother comes back, parents talk about Sara's pajamas))

3 M: ((turns from father to Sara, embraces Sara))

4 S: ((starts moving toward the bedroom door and away

5 from mother))

6 M: ((withdraws her embrace))

7 S: ((moves with her boat toward the door))

8 M: ((approaches father to take Sara's pajamas))

9 S: ((stops, turns, and looks at mother))

10 M: ((takes pajamas and starts moving toward Sara))

$11 \mathrm{~S}: \quad$ (turns from mother toward door))

$12 \mathrm{M}$ : ${ }^{\circ} \mathrm{kom} \mathrm{nu}{ }^{\circ}$ ${ }^{\circ}$ come on now ${ }^{\circ}$ ((starts waving with pajamas from behind))

13 S: ((starts "sailing" the boat toward the door and

14 her room))

15 M: ((walks slowly behind Sara, rhythmically

16 waving the pajamas))

20 S: dom reser they're traveling

21 M: vart ska dom åka då? where are they going then?

22 S: till rummet to the room

$23 \mathrm{M}$ : till ditt rum. to your room.

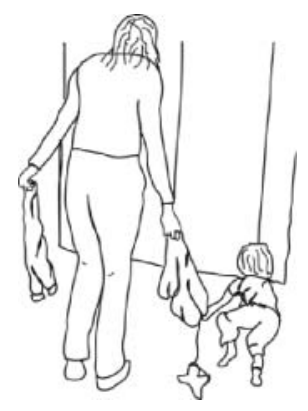

While standing in the attached laundry room, the mother issues another directive kom nu Sara 'come now Sara', with a "weary" voice quality and elongated vowel indexing "tired," "exhausted" affective stance (line 1). Upon returning to the room, the mother reinitiates the directive sequence but uses embodied actions instead: She establishes a C-formation, positioning herself behind the girl, who is playing with a toy boat on the floor. 


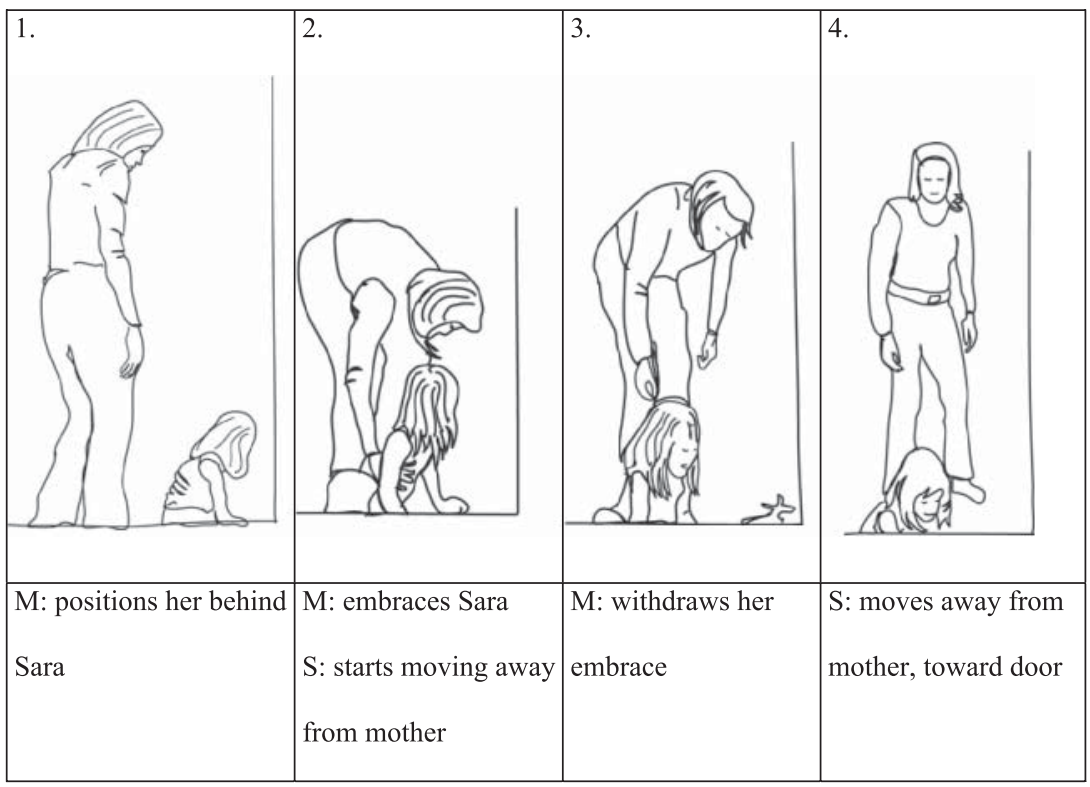

Figure 5. Withdrawn body twist

This formation allows the mother to encapsulate and constrain the physical environment available for the girl's movement (Picture 1, Figure 5). The mother then reaches down and embraces the girl from behind, holding both her hands on Sara's trunk (Picture 2). The design and quality of the tactile engagement bears close resemblance to the full embrace, deployed in another family (Excerpt [2]). It allows the parent to get a steady grip on the child's body before engaging in a body twist, and displays the mother's readiness to intervene in the child's activity.

Interestingly, the daughter immediately starts moving toward the door and the mother withdraws her embrace (without instantiating a complete body twist) (Pictures 2-4). The daughter's locomotion demonstrates that her mother's tactile engagement is recognizable as an initial phase of a body twist that projects a particular sequence of actions within the directive trajectory, namely, (i) it solicits the recipient's recasting of her body positioning (toward the target-activity-relevant location), (ii) marks a juncture between two activity frameworks, and (iii) implicitly prompts the child's locomotion.

After a short side sequence, the mother re-uptakes her request (a repetitive imperative kom 'come', line 12), while still positioned behind the 
girl. ${ }^{7}$ Notably, the daughter re-starts her movement toward her room (the location implicated by her mother's directive), framing it as a playful way of complying with her mother's request (asserting her terms as to how to accomplish the requested locomotion to her room): she proceeds slowly to her room, keying her movements as the toy boat's playful trip. The mother also aligns with this nonserious affective keying of locomotion: All the way to the daughter's bedroom, she sustains a C-formation and deploys non-tactile steering by playfully waving the daughter's pajamas from behind. Similar to the non-tactile steering in Excerpt (3), the mother's movements and "waving" gestures delineate the direction of the girl's movements; at the same time, the continuity of "waving" functions as a constant reminder of the relevant action (i.e., locomotion forward). The (social) contract (Aronsson and Cekaite 2007) concerning the targetactivity-relevant action trajectory is silently acknowledged, and is effectuated through the participants' concerted nonverbal actions. Only occasionally is it brought up in their talk (lines 20-23).

\section{Concluding discussion}

As demonstrated, embodied actions featured as key aspects in the design of parental directives in mundane family interactions. Parental control, assistance, and socialization were inextricably reliant on bodily practices, sensitizing the child's awareness of the interrelatedness of body actions and talk and of the embodied and spatial features of social conduct and social accountability.

In line with earlier work on directive trajectories (M. Goodwin 2006; Tulbert and M. Goodwin forthcoming), the present study demonstrates the significance of embodied actions and spatial formations, highlighting in detail a distinct type of the directive trajectories that was furnished with systematic techniques of the body. Parental shepherding moves were assembled through tactile engagement and what here is called C-formation aimed at monitoring the child's body for compliance. The body twist, as a form of parental tactile intervention, was used as a multidirectional device, aimed at reactively terminating the recipient's ongoing activity and proactively establishing ground for a new course of action. By deploying a body twist, the parent changed the angle of the child's bodily orientation, reorienting the child toward the location for the new course of action. Furthermore, the body twist allowed the parent to arrange the participants' bodies into a C-formation (embodied formation of control), where the parent, while positioned behind the child, was provided with privileged (visual and bodily) access enabling monitoring of the child's 
actions. Steering the child through the route of locomotion to the location of the target activity constituted another segment within the directive sequence. It consisted of interactionally meaningful tactile and non-tactile acts through which the parents projected, scaffolded, and controlled the child's movements toward the requested goal (while the participants actively maintained a mobile C-formation). As part of this process, the participants smoothly coordinated their bodies within the joint activity framework, constituted through co-established (through physical alignment) embodied perceptual structures (e.g., Tulbert and M. Goodwin forthcoming).

From a dialogic perspective on embodied nature of human interaction, the study has highlighted the relational and responsive nature of touch, foregrounding ways in which tactile engagement was employed as significant means for coordinating embodied social interaction. Interaction, including the tactile perceptual mode, was a dynamic process that unfolded at a temporal horizon: Directive trajectories involved sequences of touches deployed recursively to respond to and influence the ongoing production of the intentional action. Tactile engagement was not only a method for taking in, but also of giving information, notably about the recipient's alignment with the co-participant's suggested course of action. Touch behaviors were acted upon as meaningful constituents of the overarching, dynamically developing activity frameworks and functioned as perceptually salient resources for indexing, renewing, and developing the social and affective relations of the participants. Distinct forms of touch behavior (Excerpts [1] and [2]) were combined with C-formation to produce socioculturally significant meanings (inviting specific forms of the recipient's uptake), suggesting that the coupling between touch and bodily positionings of the participants is a factor that needs to be taken into account when analyzing the interactional functions of touch.

Notably, embodied directives demonstrate how social order, mutual accountability, and trust are produced and instantiated through family members' moment-to-moment participation in everyday interactions. Directives provided indexical resources for the co-construction of a broad range of social roles in family life (e.g., the autonomous, trustworthy, docile, or disobedient child) and allowed parents to distinctly situate themselves as relevant, or to downplay their relevance to the ongoing construal of action. Predominantly neutral affective indexing indicates that shepherding forms were part and parcel of family life. Viable due to the intimate but asymmetric power relations established between the participants (based on a taken-for-granted, basic sense of trust), they provided interactional tools for managing the balance between the need for social control, socialization, and the social integrity of the child. 
In fact, embodied shepherding moves can be seen as indexical of the dialectics of care and control, power and intimacy co-present in parentchild relations, demonstrating that both taken-for-granted and reflective forms of trust are evident at the level of situated family interactions. Across the families, the interactional development of directive trajectories shows parental work done in order to be able to direct and control the child's actions through predominantly verbal methods, and highlights the everyday socialization as it is accomplished through situated intersubjective displays of reflective trust. Such verbal directives position the child as responsible and trustworthy, i.e., able to bring about the requested action by himself. Simply put, then, shepherding actions (tactile intervention) that were recurrently deployed responsively to numerous unsuccessful verbal directives can be seen as situated embodied displays of the parent's distrust in the child's willingness to initiate the requested action on her/his own. While shepherding moves were employed with the children within a broad age span (from three- to twelve-year-olds), some differences concerning the age of the children are worth commenting on. Overall, the parents tended to exert a greater degree of embodied control on younger children, using touch of different quality and design, "orchestrating" the children's movement through tactile steering as opposed to leaving the children to move and act by themselves (e.g., Excerpt [3]). With increased age of the children, bodily control can be seen to gradually give way to more "long-distance verbal monitoring" (de Leon 2000: 151) and non-tactile steering, which position the children as trustworthy and capable of bringing about the relevant activity by themselves and insist on their acting as such. ${ }^{8}$

When set in the appropriate ethnographic context, detailed analysis of directives shows that embodied facets of participation (touch and Cformation), traditionally absent from the canonical models of adult-child interaction, were significant interactional resources in Swedish middleclass parent-child interactions. Overall, the embodied directives served as multifunctional cultural tools that scaffolded the child's reflexive awareness of the relational and dialogical aspects of social action that, in addition to speech, rely on culturally inscribed techniques of the body (cf. Mauss 1973). Theoretically, our understanding of the communicative patterns that shape the child's development (Vygotsky 1978) can thus be deepened by conceiving of this socialization context as an inherently multimodal framework for participation, established, co-assessed, and reshaped through socioculturally meaningful bodily and spatial practices (C. Goodwin 2000). Instead of a canonical face-to-face exchange of verbal messages, we may discover embodied practices, i.e., powerful resources scaffolding the child's mastery of bodily and verbal actions as a 
synthetic unity (Merleau-Ponty 1962: 147) through which participation in social life is accomplished.

\section{Appendix: Transcription conventions}

$\begin{array}{ll}: & \text { Prolonged syllable } \\ \text { [ ] } & \text { Overlapping utterances } \\ (.) & \text { Micropause, i.e., shorter than (0.5) } \\ (2) & \text { Pauses in seconds } \\ x & \text { Inaudible word } \\ \text { (xx) } & \text { Unsure transcription } \\ \circ \circ & \text { Speech in low volume } \\ \text { YES } & \text { Relatively high amplitude } \\ (()) & \text { Further comments of the transcriber } \\ \rangle\langle & \text { Quicker pace than surrounding talk } \\ \langle\rangle & \text { Slower pace than surrounding talk } \\ ? & \text { Rising terminal intonation } \\ \dot{k} & \text { Falling terminal intonation } \\ \text { kissa } & \text { Sounds marked by emphatic stress } \\ \text { heh } & \text { Laughter } \\ \uparrow \downarrow & \text { Rising, falling intonation }\end{array}$

\section{Notes}

* I would like to thank Karin Aronsson, Daniel Persson Thunqvist, Cecilia Wadensjö, and the anonymous reviewers for the insightful comments, and Ian Dickson for assistance with the line drawings. Financial support from Alfred P. Sloan Foundation, project "Everyday lives of working families. Italy, Sweden and the United States" (led by Karin Aronsson and Clotilde Pontecorvo, in a coordinated effort with Elinor Ochs and her collaborators at the CELF centre at UCLA), is gratefully acknowledged.

1. The present data are a part of a large-scale video ethnography, documenting middleclass dual-earner family life in the United States, Italy, and Sweden. Thus far, video ethnographic data documenting in detail how Swedish families juggle their everyday demands are rather unique.

2. While directive sequences (22) to children between three and six years of age entailed body twist and tactile/non-tactile steering, ten sequences directed at older children (812 years) involved body twist and non-tactile forms of steering. Importantly, considering the cross-sectional rather than longitudinal design of the study, findings concerning the relation between children's age and tactile engagement are suggestive rather than conclusive and need to be treated tentatively.

3. See the appendix for the transcription conventions, which follow the Jeffersonian transcription system. 
4. In his study of a disciplining practice of "time-out," McIlvenny (2009) described a D-formation ("incipient disciplinary formation") that, despite vis-à-vis arrangement of co-participants' bodies, is characterized by the child's lack of control over the maintenance of this formation and his unequal access to the other's transactional segment. The C-formation, too, is characterized by asymmetry, but is assembled through a different spatial-orientational arrangement.

5. Affectively aggravated tactile actions are rare in the present corpus, probably due to the integrity-heavy character of affectively negative tactile intervention (cf. Jones and Yarborough 1985).

6. C-formation and tactile steering are not confined to parent-child interactions. Between adults, for instance, this formation can serve as an archetypical formation of surveillance and powerlessness (e.g., between a guard and a prisoner).

7. Notably, lines $8-11$ indicate that Sara coordinates her actions with her mother's, interrupting her locomotion toward the door and, later, re-uptaking bodily position relevant to goal-oriented locomotion according to the mother's main or subordinate interactional involvements.

8. Through participation in the everyday directive trajectories, I suggest, the child can be scaffolded to develop a sense of oneself and one's actions as trustworthy or not trustworthy by acting upon and responding to the understanding of her/his actions through the perspective of the other (the parent), as it is displayed through the embodied design of parental directives. She/he is thereby scaffolded to develop and interactionally demonstrate "Self's perspective on Other's perspective on Self and Other," see Gillespie (2008: 276).

\section{References}

Aronsson, Karin \& Asta Cekaite. 2007. Getting things done in family life: Directives and activity contracts. Paper presented at the 10th International Pragmatics Conference, Gothenburg, Sweden.

Aronsson, Karin \& Mia Thorell. 1999. Family politics in children's play directives. Journal of Pragmatics 31. 25-47.

Blum-Kulka, Shoshana. 1997. Dinner talk. Cultural patterns of sociability and socialization in family discourse. Mahwah, NJ: Lawrence Erlbaum.

Brown, Penelope \& Stephen C. Levinson. 1987. Politeness. Some universals in language usage. Cambridge: Cambridge University Press.

Brumark, Åsa. 2006. Regulatory talk and politeness at the family dinner table. Pragmatics $16(2 / 3) .171-212$.

de Leon, Lourdes. 2000. The emergent participant: Interactive patterns in the socialization of Tzoltil (Mayan) infants. Journal of Linguistic Anthropology 8(2). 131-161.

Erikson, Erik. 1968. Identity: Youth and crisis. London: Faber \& Faber.

Ervin-Tripp, Susan. 1976. "Is Sybil there?" The structure of some American English directives. Language in Society 5. 25-67.

Ervin-Tripp, Susan, Jiansheng Guo \& Martin Lampert. 1990. Politeness and persuasion in children's control acts. Journal of Pragmatics 14. 307-331.

Farnell, B. 1999. Moving bodies, acting selves. Annual Review of Anthropology 28. 341373.

Fasulo, Alessandra, Heather Loyd \& Vincenzo Padiglione. 2007. Children's socialization into cleaning practices: A cross-cultural perspective. Discourse \& Society 18(1). 11-33. 


\section{Asta Cekaite}

Gillespie, Alex. 2008. The intersubjective dynamics of trust, distrust, and manipulation. In Ivana Markova \& Alex Gillespie (eds.), Trust and distrust. Sociocultural perspectives, 273-290. Charlotte, NJ: Information Age Publishing.

Goodwin, Charles. 2000. Action and embodiment within situated human interaction. Journal of Pragmatics 32. 1489-1522.

Goodwin, Charles. 2007. Participation, stance and affect in the organization of activities. Discourse \& Society 18(1). 53-73.

Goodwin, Marjorie Harness. 2006. Participation, affect, and trajectory in family directive/ response sequences. Text and Talk 26. 515-544.

Guerrero, Laura K. \& Kory Floyd. 2006. Nonverbal communication in close relations. Mahwah, NJ: Lawrence Erlbaum.

Hanks, William F. 1996. Language and communicative practices. Boulder, CO: Westview Press.

Hertenstein, Matthiew. 2002. Touch: Its communicative functions in infancy. Human Development 2002. 70-94.

Jones, Stanley E. \& Elaine A. Yarborough. 1985. A naturalistic study of the meanings of touch. Communication Monographs 52. 19-56.

Kendon, Adam. 1990. Spatial organization in social encounters. The F-formation system. In Adam Kendon (ed.), Conducting interaction. Patterns of behavior in focused encounters, 209-230. Cambridge: Cambridge University Press.

Kendon, Adam. 2000. Language and gesture: Unity or duality? In David McNeill (ed.), Language and gesture, 47-63. Cambridge: Cambridge University Press.

Lindblom, Jessica. 2007. Minding the body: Interacting socially through embodied action. Linköping: Linköping University dissertation, Linköping Studies in Science and Technology.

Linell, Per. 2009. Rethinking language, mind and world dialogically. Aspects to human sensemaking. Charlotte, NC: Information Age Publishing.

Markova, Ivana, Per Linell \& Alex Gillespie. 2008. Trust and distrust in society. In Ivana Markova \& Alex Gillespie (eds.), Trust and distrust: Sociocultural perspectives, 3-27. Greenwich, CT: Information Age Publishing.

Mauss, Marcel. 1973 [1935]. Techniques of the body. Economy and Society 2. 70-88.

McIlvenny, Paul. 2009. Communicating a "time-out" in parent-child conflict: Embodied interaction, domestic space and discipline in a reality TV parenting programme. Journal of Pragmatics 41. 2017-2032.

Merleau-Ponty, Maurice. 1962. Phenomenology of perception. C. Smith (trans.). London: Routledge \& Kegan Paul.

Neff, Kristin. 2003. Understanding how universal goals of independence and interdependence are manifested within particular cultural contexts. Human Development 46. 312 318.

Ochs, Elinor, A. Graesch, A. Mittman, T. Bradbury \& R. Repetti. 2006. Video ethnography and ethnoarcheological tracking. In M. Pit-Catsouphes, E. Ernst \& S. Sweet (eds.), Work and family handbook: Multi-disciplinary perspectives and approaches, 387-409. Mahwah, NJ: Lawrence Erlbaum.

Rogoff, Barbara. 1990. Apprenticeship in thinking: Cognitive development in social context. New York: Oxford University Press.

Schegloff, Emanuel A. 1998. Body torque. Social Research 65(3). 535-596.

Scollon, Ron \& Suzan B. K. Scollon. 1981. Narrative, literacy and face in interethnic communication. Norwood, NJ: Ablex.

Tulbert, Eve \& Marjorie Harness Goodwin. forthcoming. Choreographies of attention. Multimodality in a routine activity. In Charles Goodwin, D. LeBaron \& Jürgen Streeck (eds.), Multimodality in communication. Cambridge: Cambridge University Press. 
Uzgiris, Ina. 2000. Words don't tell all: Some thoughts on early communication development. In Nancy I. Budwig, Ina Uzgiris \& Jim Wertsch (eds.), Communication: An arena of development, 131-142. Stamford: Ablex Publishing.

Vygotsky, Lev. 1978. Mind in society, M. Cole (trans.). Cambridge, MA: Harvard University Press.

Wingard, Leah. 2006. Mentioning homework first in parent-child interaction. Text \& Talk 26. $573-598$.

Asta Cekaite is Assistant Professor at the Department of Child Studies, Linköping University, Sweden. Her research interests include first- and second-language socialization, embodied and affective features of social interaction, and children's discourse in formal and informal (family and peer group) settings. She has published in Discourse Studies, Applied Linguistics, Modern Language Journal, International Journal of Multilingualism. Address for correspondence: Department of Child Studies, Linköping University, 58183 Linköping, Sweden〈asta.cekaite@liu.se〉. 